Chapter 9

\title{
Influence of the Nutrition on Bone Health of Children and Adolescents
}

\author{
Emilio González-Jiménez \\ Additional information is available at the end of the chapter \\ http://dx.doi.org/10.5772/54773
}

\section{Introduction}

Maintaining adequate nutritional status, is an essential factor for bone growth and mineralization. Both processes, both the increase in size and development through the deposit of minerals pass alongside and under the regulation by different factors [1]. In this sense, acquired during childhood and adolescence adequate bone mass will be a prime target for complications, not only in childhood and adolescence but during adulthood [2].

Currently, in developed countries, osteoporosis is a serious public health problem that affects mainly children and adolescents as a consequence of sedentary lifestyle and unhealthy eating habits [3].

Recent studies suggest that osteoporosis prevention should begin in childhood. Children and adolescents should achieve an adequate peak bone mass (PMO) before the end of its growth. Otherwise, they may develop osteopenia or osteoporosis early, with a high risk of fractures and consequently a lower quality of life [4].

Given that the risk of developing osteoporosis depends in $60-80 \%$ of genetic factors on which we can not intervene, we must act on those other environmental factors involved which if capable of being corrected, mainly food [5]. It is known that bone mineral density (BMD) is modifiable by diet and exercise as much as $20 \%$. Nutrients ingested daily through food involved in the development and maintenance of adequate bone mineralization by means of different processes, favoring the differentiation of bone tissue functional cells (osteoblasts and osteoclasts) and acting as plastics elements. In addition, provide adequate nutrition essential vitamins involved in bone matrix synthesis and calcium absorption at intestinal level, also allowing the synthesis of certain hormones and growth factors involved [6]. 
Therefore, based on the above premises, childhood and adolescence are important periods in which an adequate nutrition will firmly prevent the development of osteopenia or osteoporosis at an early age [7].

\section{Nature of bone tissue and skeletal development}

Bone consists of cells (2-5\%) and in a largely inert matter (95-98\%), ie basically protein and minerals [8]. From a structural standpoint, the protein component is composed of fibers of collagen type I and gla protein (osteocalcin, osteonectin, fibronectin, osteopontin and bone sialoprotein). Its component consists mainly of hydroxyapatite mineral-rich carbonates (37-40\% calcium and phosphate 50-58\%) and to a lesser extent sodium, potassium, magnesium and citrate [8].

At birth, the newborn already has 70 to 95 grams of bone mass approximately equivalent to $4 \%$ by weight. During adolescence, girls have 2,400 grams of bone [9]. The boys, meanwhile, are at increased volume estimated at approximately 3,300 grams. Both quantities correspond to a $85 \%$ to development of the cortical bone and $15 \%$ of the cancellous bone development [9].

In this sense, it is considered that the girls get their peak bone mass at age 18 as opposed to boys who reach it some years later, at the age of 23 years or so [9]. The gain of this peak is mediated by the action of sex hormones on growth factor 1 (IGF-1), which is stimulated in parallel mode by proteins [10].

Once acquired peak bone mass, it will tend to stabilize. After bone mass will be reduced only to certain pathological processes involving a state of prostration of the patient or following the administration of certain drugs such as glucocorticoids [11]. Although the bone loss does not occur evenly across the skeleton. Normally, women aged between 20 and 30 begin to develop a reduced bone loss $(<1 \%)$ level of the vertebrae [12]. It will be during the first 5 years postmenopause when the loss increases between 2 and $6 \%$ annually. Among men, the loss occurs at older ages, ie from 50 years of age [12].

\section{Nutritional factors involved in the process of bone mineralization}

\section{Energy intake}

Maintain adequate caloric intake permitted during childhood and adolescence to ensure growth, maturation and bone mineralization process [13].

\section{Protein intake}

Protein intake, is another important factor for the formation of bone matrix. However, protein intake appears to be important risk factor among our child population as they often exceed recommendations [14]. This mainly because the food in Western countries usually contain 
plenty of eggs, meat, fish and dairy products which guarantees a significant amount of protein [14]. Moreover, low consumption of protein (less than 45-55 g/day in men or $45 \mathrm{~g} /$ day in women) are usually accompanied by a lower muscle mass and bone, this mainly due to a reduction in bone structure protein. Meanwhile, a high protein intake (greater than 2 grams/kilogram/ day) may also cause a loss of bone mass, since for each gram of protein intake in excess through the diet, results in a loss of $1 \mathrm{mg}$ of calcium [14].

\section{Calcium and phosphorus}

Both nutrients are the substances most studied for their influence on the prevention and treatment of osteoporosis. Calcium is the most abundant mineral in the human skeleton. $99 \%$ is deposited in the bone and passing about 30 grams at birth [10 grams per kilogram of body weight) to about 1,300 grams in adult (19 grams per kilogram of body weight) [15]. Now, by weight, calcium accounts for $40 \%$ of bone mineral and $60 \%$ phosphorus. From a metabolic point of view, the absorption of calcium from food depends on several factors. First of its bioavailability in the diet, the deposits of vitamin $\mathrm{D}$, the calcium / phosphorus $(\mathrm{Ca} / \mathrm{P})$ and the presence in food of substances that facilitate or interfere with its absorption [16]. In the case of phosphorus $(\mathrm{P})$, this also deposits in the bone by $85 \%$. The high presence among foods in our diet $(60-70 \%)$, guaranteed to meet the needs of our food without difficulty, especially among the young. While its excessive intake may alter the $\mathrm{Ca} / \mathrm{P}$ thus hindering the absorption of calcium [17].

\section{Calcium-phosphorus balance}

The study of calcium-phosphorus balance is complex when you consider its high fecal excretion. In the case of calcium, their daily loss (through excretion in the urine, fecal and dermal) are estimated at $420 \mathrm{mg} /$ day. Calcium is absorbed in the intestine not ever exceeding $30 \%$ of the total amount ingested [18]. For absorption, calcium must compete with other substances such as phytates and oxalates act by inhibiting its absorption. The solubilized calcium in foods like milk or juice is absorbed supplemented with ease. In the case of phosphates, these are found in a wide variety of foods thereby showing a higher bioavailability than calcium. His diet recommendations are estimated at 700-800 $\mathrm{mg} /$ day in adults compared to $1200 \mathrm{mg} /$ day estimated as necessary during adolescence. For its part, has a phosphorus antiosificante effect by increasing the secretion of PTH and reduced intestinal calcium absorption [18].

\section{Recommendations for calcium intake}

In the case of calcium, recommendations vary depending on the stage of life where we are. For children under 1 year and for both sexes, the recommended intake of between 400-600 mg/day of calcium. During adolescence, the recommendations are found up to $1200 \mathrm{mg} /$ day for both sexes [19]. For adult males, the recommendations provide a daily intake of between 800 to 1000 mg/day. For adult women the recommendations are higher, between 1200 and $1500 \mathrm{mg} /$ day for those postmenopausal women in gestation and during lactation [20]. According to recent studies, $60 \%$ of the calcium in our diet comes from foods such as dairy products, followed by $13 \%$ from foods such as cereals, $15 \%$ from fruits, vegetables, legumes, while not as only $6 \%$ comes from foods like meat, fish or eggs. This entails risks if it is very sedentary children and 
adolescents and women with menopause. In some cases this will be indicated calcium supplementation, especially through the diet is not achieved optimal calcium intake. In the study by Johsnton et al (1992) [21], from a population of prepubertal twins who are supplemented with a dose of $700 \mathrm{mg} /$ day of calcium, managed to increase its process of mineralization and bone mass in a $5 \%$.

\section{Sodium intake}

Excessive sodium intake in the diet may be accompanied by a reduction in bone mineral density. This decrease in bone mass is mediated by a renal calcium excretion [22]. In this regard, given an approximate intake of $450 \mathrm{mg}$ of sodium in the diet, the kidney is capable of removing in parallel up to $10 \mathrm{mg}$ of calcium. Accordingly, the recommendations established for calcium intake in adolescents, they must not exceed a daily sodium intake greater than $2000 \mathrm{mg}$ or what is just 5 grams of salt [22].

\section{Intake of vitamin $\mathrm{D}$ and $\mathrm{K}$ and its importance in the process of bone mineralization}

Vitamin D belongs to the group of so-called fat-soluble vitamins. Their presence in food is by way of cholecalciferol (D3) and ergocalciferol. Usually has its origin in cholesterol or ergosterol derivative which is converted to ergocalciferol (D2) the effect of ultraviolet radiation. However, the active form of this vitamin is called calcitriol [23]. Its synthesis is closely associated with sun exposure, that is, with a daily sun exposure is insufficient to meet the physiological needs of the vitamin in our body [24]. Their presence facilitates the absorption of calcitriol in the intestine. In this regard, serum levels of this vitamin have been correlated with bone density in certain locations such as the lumbar spine and femoral neck. Another vitamin involved in the process of bone mineralization during childhood and adolescence is vitamin K. Participates in the process of carboxylation of osteocalcin and thereby cause a deficit decreased and carboxylation of osteocalcin synthesis [25]. Fluorine Within the elementary ions, fluoride in nature and chemical behavior is the most active of all elementary ions. Its concentration is high in mineral water, fish, tea and certain meals [26]. Fluoride ingested through the diet, is rapidly absorbed from the gastrointestinal tract to blood from which will be distributed to tissues and organs by simple diffusion. Among its benefits to bone level highlights its ability to stimulate osteoblast activity, increasing the mainly trabecular bone. In this regard, it has been demonstrated that administration of $25 \mathrm{mg} /$ day slow-release fluoride supplied for 4 years reduces the incidence of vertebral fractures [26]. Consumption of carbonated drinks

The increased consumption of carbonated beverages is associated with a progressive decrease in milk intake, has led to high consumption of phosphoric acid associated with calcium deficiency [27]. This eating pattern will have consequences for bone health, because when a diet is high in phosphorus and low in calcium, bone resorption increases to recover the serum levels of this mineral. There are epidemiological studies that linked the consumption of carbonated beverages to an increased risk of fracture in children and young girls. However, there is some controversy about this relationship [28]. Many authors, conclude that the major effect of carbonated beverages is mainly due to displacement of milk in the diet, especially among young people. 


\section{Alcohol consumption, snuff and caffeine}

Excessive alcohol consumption, is an important risk factor for osteoporosis, especially among young males. Ingestion, causes a decrease in bone mass through an alteration of the formation and bone remodeling [29]. During adolescence, a high intake of alcohol reduces bone mass peak. This circumstance enables the development of osteopenia or osteoporosis at an early age [30]. In addition, alcohol intake is associated with dietary disorders, which adversely affect the bone metabolism. Thus, their intake is related to a deficiency of vitamin D and parathyroid hormone (PTH), hypoproteinemia, liver, hypomagnesemia, deficit B vitamins and folic acid, iron overload and decreased testosterone [31].

Regarding the consumption of snuff in adolescents, it has been associated with a significant reduction in bone mineral density (BMD). It has been shown that adolescent smokers, especially girls, have a lower bone mineral density and increased rate of bone loss that girls do not smoke. This has been demonstrated also among male adolescents [32].

Regarding caffeine intake, it increases urinary calcium excretion during the first 3 hours after ingestion. It has been found that a daily intake of two or more cups of coffee, is correlated with lower bone mineral density in these subjects.

\section{In conclusion}

Among all the factors involved in the mineralization of bone mass, maintaining a balanced diet is a key factor. A balanced and varied diet will be the best procedure to ensure proper bone development among young people. Therefore, an adequate energy and protein intake, coupled with a contribution provided essential nutrients such as calcium, phosphorus or fluorine and certain vitamins such as D and $\mathrm{K}$ Assume the basic nutritional elements to ensure adequate bone mass during the later stages early in life. Given that bone development achieved during childhood and adolescence will influence the health status and bone mass in adulthood and that this depends largely on food, care for the food of the young should be a prime target order.

\section{Author details}

\section{Emilio González-Jiménez*}

Address all correspondence to: emigoji@ugr.es

Department of Nursing. Faculty of Nursing (Campus of Melilla), University of Granada, Melilla, Spain 


\section{References}

[1] Jones, G. Early life nutrition and bone development in children. Nestle Nutr Workshop Ser Pediatr Program (2011). , 68, 227-33.

[2] Tristán Fernández JMRuiz Santiago F, Pérez de la Cruz A, Lobo Tañer G, Aguilar Cordero MJ, Collado Torreblanca F. Influencia de la nutrición y del entorno social en la maduración ósea del niño. Nutr Hosp (2007). , 22, 417-24.

[3] Quesada Gómez JMSosa Henríquez M. Nutrición y osteoporosis. Calcio y vitamina D. Rev Osteoporos Metab Miner (2011). , 4, 165-82.

[4] Adami, S, Isaia, G, Luisetto, G, Minisola, S, Sinigaglia, L, Silvestri, S, et al. ICARO Study Group. Osteoporosis treatment and fracture incidence: the ICARO longitudinal study. Osteoporos Int (2008). , 19, 1219-23.

[5] Bechtold-Dalla Pozza SBone density measurements on growing skeletons and the clinical consequences. Z Rheumatol (2011). , 70(10), 844-52.

[6] Cashman, K. D. Diet, Nutrition, and Bone Health. J Nutr (2007). S, 2507-12.

[7] Hirota, T, \& Hirota, K. Nutrition in bone growth and development. Clin Calcium (2011). , 21(9), 1329-33.

[8] Qiu, Z. Y, Li, G, Zhang, Y. Q, Liu, J, Hu, W, Ma, J, \& Zhang, S. M. Fine structure analysis and sintering properties of Si-doped hydroxyapatite. Biomed Mater (2012).

[9] Mora, S, \& Gilsanz, V. Establishment of peak bone mass. Endocrinol Metab Clin N Am (2003). , 32, 39-63.

[10] Zofková, I. Soft tissues, hormones and the skeleton. Vnitr Lek (2012). , 58(2), 135-39.

[11] Krall, E. A, \& Dawson-hughes, B. Osteoporosis: En: Shils ME, Olson JA, Ross AC, editores. Nutrición en Salud y Enfermedad. México, Interamericana, (2002).

[12] Zatonski, T, Temporale, H, \& Krecicki, T. Hearing and balance in metabolic bone diseases. Pol Merkur Lekarski (2012). , 32(189), 198-201.

[13] Zagarins, S. E, Ronnenberg, A. G, Gehlbach, S. H, Lin, R, \& Bertone-johnson, E. R. Are existing measures of overall diet quality associated with peak bone mass in young premenopausal women? J Hum Nutr Diet (2012). , 25(2), 172-79.

[14] Bonjour, J. P. Protein intake and bone health. Int J Vitam Nutr Res (2011).

[15] Caroli, A, Poli, A, Ricotta, D, Banfi, G, \& Cocchi, D. Invited review: Dairy intake and bone health: a viewpoint from the state of the art. J Dairy Sci (2011). , 94(11), 5249-62.

[16] Food and Nutritional BoardDietary Reference Intakes (DRI) for calcium, phosphorus, magnesium, vitamin D and fluoride. Washington: National Academy of Sciences. National Academy Press; (1997).

[17] Bonjour, J. P. Bone mineral adquisition in adolescente. En: Markus R, Felman D, Kesley J, editores. Osteoporosis. San Diego: Academic Press; (1996). , 465-476.

[18] Loui, A, Raab, A, Obladen, M, \& Brätter, P. Calcium, phosphorus and magnesium balance: FM 85 fortification of human milk does not meet mineral needs of extremely low birthweight infants. Eur J Clin Nutr (2002). , 56(3), 228-35. 
[19] Basabe, B, Mena, M. C, Faci, M, Aparicio, A, López-sobaler, A. M, \& Ortega, R. M. Influencia de la ingesta de calcio y fósforo sobre la densidad mineral ósea en mujeres jóvenes. Arch Latinoam Nutr (2004). , 54, 203-8.

[20] Jackson, R. D. LaCroix AZ, Gass M, Wallace RB, Robbins J, Lewis CE, et al. Calcium plus vitamin D supplementation and the risk of fractures. N Engl J Med (2006). , 354, 669-83.

[21] Johsnton, C. C, Miller, J. Z, Siemenda, C. W, Reister, T. K, Hui, S, \& Christian, J. C. Calcium supplementation and increases in bone mineral in children. $\mathrm{N}$ Engl J Med (1992). , 82-87.

[22] Chan, R, Woo, J, Lau, W, Leung, J, Xu, L, Zhao, X, Yu, W, Lau, E, \& Pocock, N. Effects of lifestyle and diet on bone health in young adult Chinese women living in Hong Kong and Beijing. Food Nutr Bull (2009). , 30(4), 370-78.

[23] Holick, M. F, \& Chen, T. C. Vitamin D deficiency: A world wide problem with health consequences. Am J Clin Nutr (2008). , 87, 1080-86.

[24] Holick, M. F. Vitamin D deficiency. N Engl J Med (2007). , 357, 266-81.

[25] Ahmadieh, H, \& Arabi, A. Vitamins and bone health: beyond calcium and vitamin D. Nutr Rev (2011). , 69(10), 584-98.

[26] Grajeta, H. Nutrition in prevention and treatment of osteoporosis. Przegl Lek (2003). , $60(10), 649-53$.

[27] Ma, D, \& Jones, G. Soft drink and milk consumption, physical activity, bone mass, and upper limb fractures in children: a population-based case-control study. Calcif Tissue Int (2004). , 75(4), 286-91.

[28] Wyshak, G. Teenaged girls, carbonated beverage consumption, and bone fractures. Arch Pediatr Adolesc Med (2000). , 154(6), 610-13.

[29] Chakkalakal, D. A. Alcohol-induced bone loss and deficiente bone repair. Alcohol Clin Exp Res (2005). , 29, 2077-90.

[30] Turner, R. T. Skeletal response to alcohol. Alcohol Clin Exp Res (2000). , 24, 1693-701.

[31] Kim, M. J, Shim, M. S, Kim, M. K, Lee, Y, Shing, Y. G, Churg, C. H, et al. Effect of chronic alcohol ingestión on bone mineral density in males without liver cirrosis. Korean J Intern Med (2003). , 18, 174-80.

[32] Vogt, M. T, Hanscom, B, Lauerman, W. C, \& Kang, I. D. Influence of smoking on the health patients. The National Spine network data base. Spine (2002). , 27, 313-19. 
